\title{
Operational application and improvements of the disease risk forecast model PROCULTURE to optimize fungicides spray for the septoria leaf blotch disease in winter wheat in Luxembourg
}

\author{
J. Junk ${ }^{1}$, K. Görgen ${ }^{1}$, M. El Jarroudi ${ }^{2}$, P. Delfosse ${ }^{1}$, L. Pfister ${ }^{1}$, and L. Hoffmann ${ }^{1}$ \\ ${ }^{1}$ Centre de Recherche Public - Gabriel Lippmann, 41 rue du Brill, 4422 Belvaux, Luxembourg \\ ${ }^{2}$ Université de Liège-Campus d'Arlon, 185 Avenue de Longwy, 6700 Arlon, Belgium
}

Received: 20 December 2007 - Revised: 25 April 2008 - Accepted: 8 May 2008 - Published: 22 May 2008

\begin{abstract}
The model PROCULTURE has been developed by the Université Catholique de Louvain - UCL (Belgium) to simulate the progress of the septoria leaf blotch disease on winter wheat during the cropping season. The model has been validated in Luxembourg for four years at four distinct representative sites. It is able to identify infection periods due to the causal agent Mycosphaerella graminicola on the last five leaf layers by combining meteorological data with phenological data from PROCULTURE's crop growth model component. The meteorological forcing consists of hourly time-series of air temperature, relative humidity and cumulative rainfall since the time of sowing, retrieved from automatic weather stations for hindcast and numerical weather prediction model outputs for the forecast periods. In order to improve the model, leaf wetness - which is one of the most important drivers for the spread of the disease - shall be added as an additional predictor. Therefore leaf wetness sensors were set up at four test sites during the 2007 growing season. To get a continuous spatial coverage of the country, it is planned to couple the PROCULTURE model offline to 12-hourly operational weather forecasts from an implementation of the Weather Research and Forecasting (WRF) model for Luxembourg at $1 \mathrm{~km}$ resolution. Because the WRF model does not provide leaf wetness directly, an artificial neural network (ANN) is used to model this parameter.
\end{abstract}

\section{Introduction}

A large extend of land use in the Grand Duchy of Luxembourg is agriculture and the fungal disease septoria leaf blotch is one of the major diseases in winter wheat. Its spread on the individual plant is highly dependent on rainfall events in combination with the plant's development. In order to obtain good harvests it is desirable to minimize the infection by spraying fungicides. However, fungicide application is cost intensive, should be kept to a minimum due to ecological reasons and is dependent on dry conditions to ensure a good efficacy of the treatment. Moreover, the state of the infection as well as upcoming rainfall events that lead to further infections are crucial elements that regulate the decision of spraying or not spraying. The objective is therefore to provide via

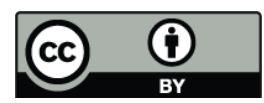

Correspondence to: J. Junk

(junk@lippmann.lu) the PROCULTURE model an optimum time frame for sitespecific spraying in an operational setup for sites throughout Luxembourg and distribute these results to the farming community.

PROCULTURE consists of a phenological wheat growth model and a plant disease model. It is able to identify infection periods caused by the causal agent $M$. graminicola on the last five leaf layers. Input to the model are phenological and disease progress observations as recalibration data and meteorological data. The latter forcing consists of hourly time-series of air temperature, relative humidity and cumulative rainfall since the time of sowing, retrieved from automatic weather stations and numerical weather prediction model outputs for the forecast periods. A weekly PROCULTURE recalibration is routinely done using actual disease levels observed on site. On average, no spray of fungicides or only one application is required to control efficiently the septoria leaf blotch disease. The PROCULTURE forecasts have been validated to be correct in about $85 \%$ of all cases 


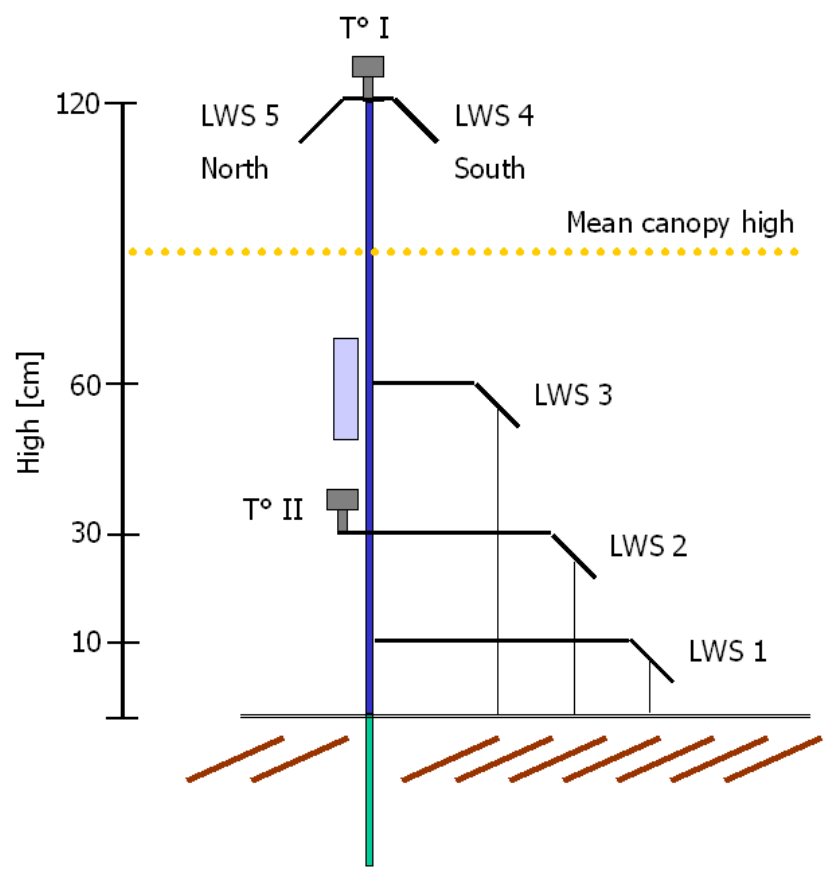

Figure 1. Set up of air temperature and leaf wetness sensors.

(Lemaire et al., 2003, El Jarroudi et al., 2002). As leaf wetness is one of the most important factors for the disease development, it shall be implemented in the disease model as a further predictor.

To get a continuous spatial coverage of PROCULTURE forecasts for M. graminicola for Luxembourg, it is planned to provide the meteorological forcing (analysis fields and 12hourly operational forecasts) by the Weather Research and Forecasting (WRF) model at $1 \mathrm{~km}$ resolution.

As the WRF model (with Noah land surface model) does not provide leaf wetness (Chen and Dudhia, 2001) as a first preparatory step in this paper we develop an artificial neural network that establishes a link among observations of leaf wetness and meteorological measurements at the five test sites during the 2007 growing season.

\section{Data and methods}

According to results from other authors like Chungu et al. (2001) or Henze et al. (2007) detailed information about the leaf wetness during the growth season can help to improve the prediction of $\mathrm{M}$. Graminicola progress on wheat plants. Therefore four test plots with winter wheat were equipped with automatic weather stations (AWS) and dielectric leaf wetness sensors (LWS) from DECAGON DEVICES during the 2007 season. The LWS were set up at $10 \mathrm{~cm}, 30 \mathrm{~cm}, 60 \mathrm{~cm}$ and $120 \mathrm{~cm}$ above the ground. To evaluate whether the sensor's orientation has any influence on the measurements, two sensors were mounted $120 \mathrm{~cm}$ above ground, orientated north and south (Fig. 1).

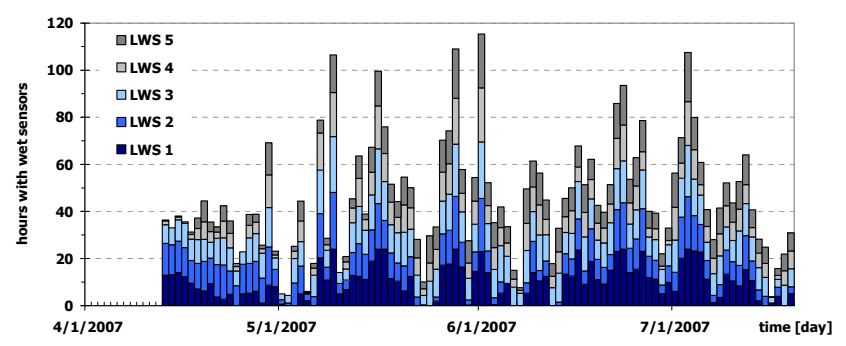

Figure 2. Cumulative time span of measured wet-leaf conditions [h d $\mathrm{d}^{-1}$ ] during the growth season of 2007 at the Reuler test site in Northern Luxembourg.

The sensor's output signal at 5-min temporal resolution can range from 445 raw counts (totally dry) up to 1.400 raw counts (totally wet). Following the advice provided by DECAGON DEVICES (2006), we used a threshold of 460 raw counts to separate dry from wet conditions. As PROCULTURE model inputs are at hourly intervals we resample the 10-min AWS (averages) as well as the leaf wetness (number of time intervals with wet sensor) measurements to hourly temporal resolutions. Additionally, the saturation vapour pressure $(\mathrm{hPa})$, the absolute humidity $\left(\mathrm{g} / \mathrm{m}^{3}\right)$ as well as the dew point $\left({ }^{\circ} \mathrm{C}\right)$ were calculated from the AWS measurements and used as predictors for the neural network.

Figure 2 gives an example of the leaf wetness conditions during the 2007 growing season for the test site at Reuler (Northern Luxembourg). In general the leaf wetness conditions at all sites show a very similar temporal pattern. In April only a few days with daily sums of up to $40 \mathrm{~h}$ of wet conditions for all sensors occurred; in May and June overall higher daily sums occurred. This study does not distinguish yet whether leaf wetness is caused by dewfall or precipitation events.

Neural networks have been applied successfully in various geo-science studies (e.g. Junk et al., 2007), including the estimation of leaf wetness duration (e.g. Francl and Panigrahi, 1997). ANNs can be used to derive a complex nonlinear relationship among (observed) input and output data without one knowing the exact physical interrelationships involved (Lopez et al., 1998).

The input data of hourly measurements of leaf wetness, air temperature, relative humidity and precipitation, as well as the calculated data of saturated vapour pressure, absolute humidity and the dew point temperature are randomly split into three data sets: for training (70\% of the data) and testing as well as validation, each accounting for $15 \%$. The training set determines the adjusted weights between the neurons. During the training period, the network is tested against the test data to determine the accuracy of the derived statistical relationship. The training procedure is stopped, as soon as the mean average error remains unchanged. Finally, the ability of the derived ANN to reproduce the validation data is verified. 
Table 1. Performance of the ANN models for the different test sites, 2007.

\begin{tabular}{lrrrrr}
\hline & Burmerange & Christnach & Everlange I & Everlange II & Reuler \\
\hline R-squared & 0.89 & 0.93 & 0.92 & 0.92 & 0.87 \\
Mean absolute error & 63.40 & 70.03 & 95.56 & 114.98 & 108.23 \\
Min. absolute error & 0.00 & 0.00 & 0.00 & 0.00 & 0.00 \\
Max. absolute error & 2272.00 & 2106.00 & 2311.00 & 2156.00 & 3163.00 \\
Percent within 5\%: & 94.41 & 94.22 & 91.79 & 89.24 & 90.56 \\
Percent within >5\% to 10\%: & 3.50 & 4.38 & 5.22 & 7.48 & 6.81 \\
Percent within >10\% to 20\%: & 1.83 & 1.25 & 2.44 & 2.99 & 2.38 \\
Percent within >20\% to 30\%: & 0.26 & 0.15 & 0.47 & 0.18 & 0.21 \\
Percent $>30 \%:$ & 0.00 & 0.00 & 0.07 & 0.11 & 0.04 \\
\hline
\end{tabular}

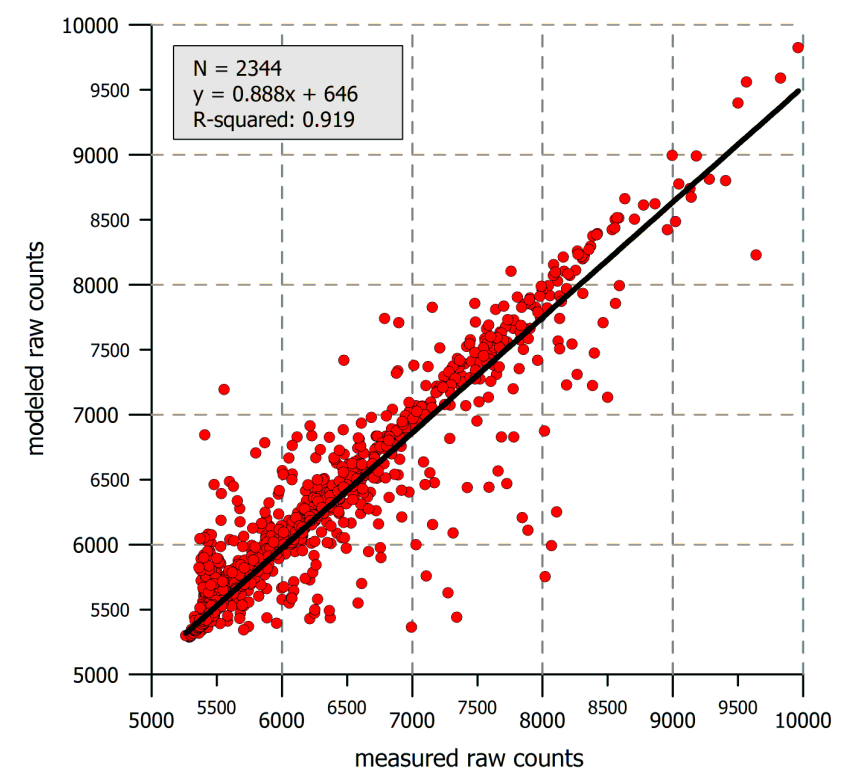

Figure 3. Scatterplot of ANN-modeled and measured hourly cumulative raw counts of LWS 3 at Burmerange; data from 13.4.2007 to 19.7.2007.

\section{Results and outlook}

Due to the fact that a multiple linear stepwise forward regression shows no satisfactory results (R-squared less than 0.6) we use artificial neural networks to model the non-linear correlation among the leaf wetness (measured in raw counts) and the meteorological conditions. Different ANN models for each test site are calculated. Validation results are shown for the test sites at Burmerange and Christnach (Figs. 3 and 4). The most relevant predictors for these sites are air temperature, relative humidity dew point temperature as well as the hours of the day.

The same calculations were done for the remaining three test sites and show very similar results (Table 1).

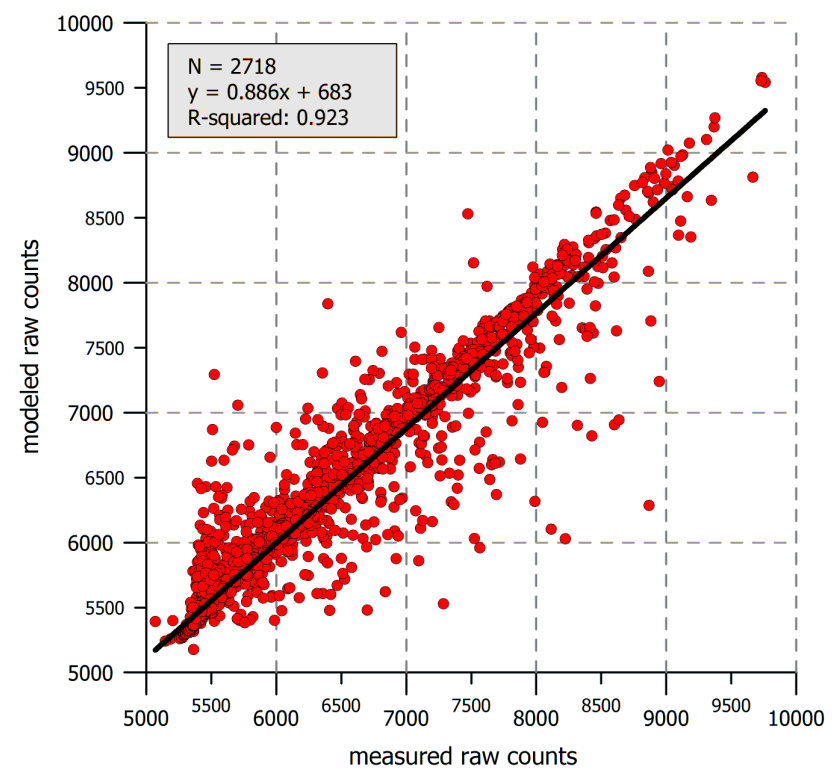

Figure 4. Scatterplot of ANN-modeled and measured hourly cumulative raw counts of LWS 3 at Christnach; data from 2.4.2007 to 24.7.2007.

Using the ANN model it is possible to reconstruct longer leaf wetness time series for the past years using only the meteorological data as input variables. This is necessary because for any improvements of the PROCULTURE model, using leaf wetness data, longer time series must be available. We will continue measuring leaf wetness in the upcoming 2008 season at the same sites with an identical sensor set up. This data will be used to evaluate the modifications of the PROCULTURE model. Furthermore it is now possible to model the duration of leaf wetness for the whole area of Luxembourg using the meteorological output of the WRF model. 
Acknowledgements. The authors are most grateful to Henri Maraite (Université Catholique de Louvain, Louvain-la-Neuve, Belgium) for providing a free licence of PROCULTURE and the Administration des Services Techniques de l'Agriculture (ASTA) for the meteorological data. They gratefully acknowledge the support from Jean-François Iffly for the maintenance of the AWS network, Cyrille Taillez for meteorological data pre processing and, Elodie Boland, Bénédicte De Vos, Virginie Schyns, and Carine Vrancken for the regular observations of the disease progress at the test sites. This project is supported by the Administration des Services Techniques de l'Agriculture (ASTA), Luxembourg, Grand Duchy of Luxembourg.

Edited by: B. Lalic

Reviewed by:one anonymous referee

\section{References}

Chen, F. and Dudhia, J.: Coupling an advanced land surfacehydrology model with the Penn State-NCAR MM5 modeling system. Part I: Model implementation and sensitivity, Mon. Weather Rev., 129, 569-585, 2001.

Chungu, C., Gilbert, J., and Townley-Smith, F.: Septoria tritici blotch development as affected by temperature, duration of leaf wetness, inoculum concentration and host, Plant Dis., 85, 430 435, 2001.
DECAGON DEVICES Inc.: Dielectric Leaf Wetness Sensor- Operator's manual, Version 1.0, USA, 2006.

El Jarroudi, M., Tychon, M. B., and Maraite, H.: Validation of "Proculture" model to predict Septoria Tritici development on winter wheat in the Grand Duchy of Luxembourg in 2001, Proceedings of the ESA VII Congress, July 15-18, 2002, Cordorba, Spain, 275-276, 2002.

Francl, L. J. and Panigrahi, S.: Artificial neural network models of wheat leaf wetness, Agr. Forest Meteorol., 88, 57-65, 1997.

Henze, M., Beyer, M., Klink, H., and Verret, J. A.: Characterizing meteorological scenarios favorable for Septoria tritici infections in wheat and estimation of latent periods, Plant Dis., 9(11), 1445-1449, 2007.

Junk, J., Feister, U., and Helbig, A.: Reconstruction of daily solar UV irradiation from 1893 to 2002 in Potsdam, Germany, Int. J. Biometeorol., 51(6), 505-512, 2007.

Lemaire, D., Amand, D., and Maraite, H.: Evolution of Proculture, a disease risk simulation model for decision taking in Mycosphaerella graminicola control, in: Global insights into Septoria and Stagonospera diseases of cereals, Proceedings of the 6th International Symposium on Septoria and Stagonospora disease of cereals, edited by: Kema, G. H. J., Van Ginkel, M., and Harrabi, M., Decembre 8-12, 2003, Tunis, Tunisia, 83-90, 2003. Lopez, G., Rubio, M. A., Martinez, M., and Battles, M.: Estimation of hourly global photo synthetically active radiation using artificial neural network models, Agr. Forest Meteorol., 107, 279291, 1998. 